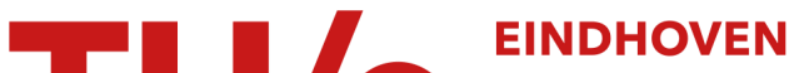 \\ UNIVERSITY OF \\ TECHNOLOGY
}

\section{Forces operative during film formation from latex dispersions}

Citation for published version (APA):

Visschers, M., Laven, J., \& Linde, van der, R. (1997). Forces operative during film formation from latex dispersions. Progress in Organic Coatings, 31(4), 311-323. https://doi.org/10.1016/S0300-9440(97)00089-1

DOI:

10.1016/S0300-9440(97)00089-1

Document status and date:

Published: 01/01/1997

\section{Document Version:}

Publisher's PDF, also known as Version of Record (includes final page, issue and volume numbers)

\section{Please check the document version of this publication:}

- A submitted manuscript is the version of the article upon submission and before peer-review. There can be important differences between the submitted version and the official published version of record. People interested in the research are advised to contact the author for the final version of the publication, or visit the $\mathrm{DOI}$ to the publisher's website.

- The final author version and the galley proof are versions of the publication after peer review.

- The final published version features the final layout of the paper including the volume, issue and page numbers.

Link to publication

\section{General rights}

Copyright and moral rights for the publications made accessible in the public portal are retained by the authors and/or other copyright owners and it is a condition of accessing publications that users recognise and abide by the legal requirements associated with these rights.

- Users may download and print one copy of any publication from the public portal for the purpose of private study or research.

- You may not further distribute the material or use it for any profit-making activity or commercial gain

- You may freely distribute the URL identifying the publication in the public portal.

If the publication is distributed under the terms of Article $25 f a$ of the Dutch Copyright Act, indicated by the "Taverne" license above, please follow below link for the End User Agreement:

www.tue.nl/taverne

Take down policy

If you believe that this document breaches copyright please contact us at:

openaccess@tue.nl

providing details and we will investigate your claim. 


\title{
Forces operative during film formation from latex dispersions
}

\author{
Marcel Visschers, Jozua Laven*, Rob van der Linde \\ Department of Polymer Chemistry and Technology, Laboratory of Coatings Technology, Faculty of Chemical Engineering and Chemistry, \\ Eindhoven University of Technology, P.O. Box 513, 5600 MB Eindhoven, Netherlands
}

Received 24 October 1996; revised version received 7 April 1997; accepted 29 April 1997

\begin{abstract}
In this paper, the different forces operative on the latex particles during film formation are examined and estimates are given of the contribution of the forces to the deformation of these particles. The forces examined are gravitational forces, Van der Waals forces, electrostatic repulsion forces due to the overlap of diffuse double layers, capillary forces due to the receding water/air interface, and capillary forces due to liquid bridges between the latex particles. The magnitude of these forces is compared to the force needed to obtain sufficient deformation, i.e. the closure of the voids between the particles. Calculations show that both capillary forces are from the same order of magnitude, $1-310^{-7} \mathrm{~N}$. The Van der Waals contribution is smaller by a factor of 20 than the contribution due to the capillary forces. However, for deformation the Van der Waals forces may be of considerable importance since the Van der Waals forces diverge for very small distances. A sound incorporation of the Van der Waals forces can be achieved by using the JKR equations. Under the assumption of constant potential, the electrostatic repulsion forces are approximately a factor of 1000 smaller than the capillary forces. The gravitational forces, $1 \times 10^{-16} \mathrm{~N}$, are negligible. The force needed for successful deformation amounts to $10^{-7} \mathrm{~N}$, assuming that the Hertz theory is applicable in the description of polymer particle deformation. Furthermore, an equation for the capillary force due to the receding water/air interface is derived which is applicable for a wider range of degrees of deformation than is the Mason-equation. Three descriptions of the particle's response to deformation are examined: (i) the Hertz theory for purely elastic spheres, (ii) the JKR-theory for purely elastic spheres in the presence of Van der Waals forces, and (iii) the Yang-theory for linear visco-elastic spheres. These descriptions are combined with both capillary forces resulting in criterions determining successful deformation. (C) 1997 Elsevier Science S.A.
\end{abstract}

Keywords: Film formation; Latex dispersion; Particle deformation forces

\section{Introduction}

The mechanism of film formation from latex dispersions has received widespread attention over the years. This attention was mainly focused on either of the three distinct processes occurring during the film formation; i.e. the initial water evaporation $[1,2]$, the subsequent particle deformation [3-8], and the final diffusion of polymer chains across the particle boundaries $[9,10]$. Regarding particle deformation, different models have been proposed in order to predict the conditions under which good final film properties, e.g. gloss, water impermeability and mechanical resistance, can be achieved. An overview of the different models has been given in a previous paper of the present authors [11]. All these theories exhibit a common trait; i.e. different driving forces are proposed without a thorough investigation of the

\footnotetext{
* Corresponding author.
}

question whether the proposed driving force is large enough to permanently deform the particles. Furthermore, for the mechanical response of the particles different models have been assumed, i.e. of a viscous, purely elastic or visco-elastic nature. In this paper, the various forces ever proposed as driving force will be examined and compared to the value needed to obtain so-called successful particle deformation. Furthermore, the implications of elastic and visco-elastic behaviour will be shown by combining different driving forces with different particles' responses.

\section{Forces operative during film formation}

\subsection{The forces in a suspension}

In principle, the forces on colloidal particles suspended in a liquid can be divided into two types: those from the sur- 
rounding liquid and those originating from the presence of other colloidal particles. The effect of the forces of the first type can be interpreted as a hydrostatic pressure (in case of a Newtonian liquid). Any part of the particle in contact with bulk liquid experiences this force from the liquid. If completely surrounded by liquid this force induces an isotropic stress within the solid particles, being numerically equal to the liquid pressure. The effect is a slight compression of the solid according to $K \Delta V / V=\Delta \mathrm{P}$, where $K$ is the compressibility modulus and $\Delta V$ is the change in volume $V$ due to a change in the pressure $\Delta P$.

Suppose a particle touches a neighbouring particle and assume that the net force is such that the particles are just not repelled from each other but also do not deform each other by being forced together. In that case, the stress condition at any point in and on the particles is unaltered at contact. As at the contact no liquid is present, it is evident than the stress condition at the solid-solid contact is isotropic with a value equal to that of the liquid pressure. The 'net' force, i.e. the measurable force between two contacting spheres therefore equals the total force minus the force of the isotropic stress in the particles due to the liquid pressure. Only external forces from e.g. receding liquid/gas interfaces, the Van der Waals interaction or the electrostatic repulsion are able to let the stress deviate from the isotropic stress condition within the particles. It is therefore useful, as we will do, to consider only the stress and accompanying forces on the particles in excess of the bulk liquid stresses because it are these excess stresses that result in a 'network' stress and, consequently, in particle deformation.

\subsection{The Van der Waals force}

When two particles are brought into close proximity, i.e. within a few nanometers, the particles experience an attractive force: the so-called Van der Waals force. The origin of this force lies in fluctuations in the charge distribution of the atoms. On atomic scale, London [12] derived an equation

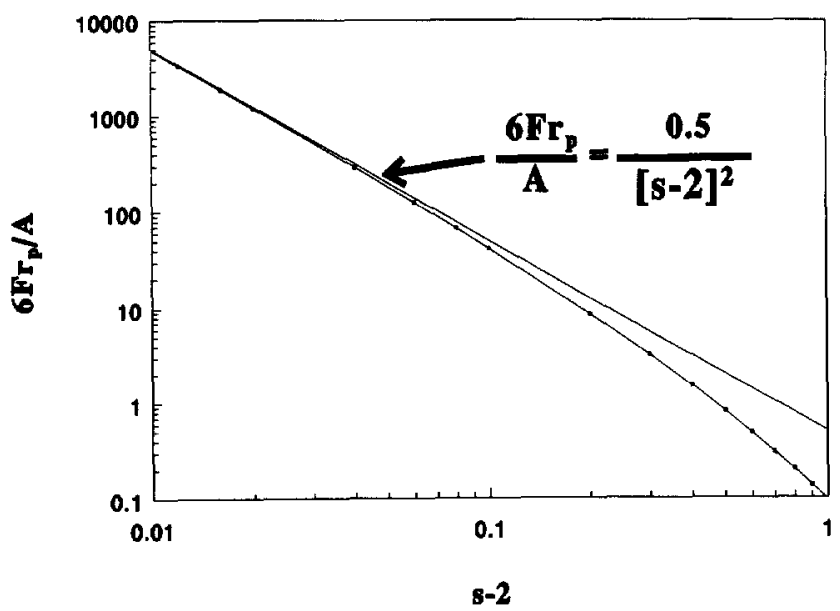

Fig. 1. The unretarded Van der Waals forces between spheres as a function of the dimensionless distances using the Hamaker theory. relating the magnitude of this force to the polarizability of the atoms. Assuming pairwise additivity, Hamaker [13] derived an equation for the Van der Waals force between macroscopic bodies. Although, the Hamaker theory is not as sophisticated as the Landau-Liftshitz theory [14] in many cases Hamaker renders a useful approach, even more so because the Landau-Liftshitz theory has not been fully developed for spherical objects. Although Hamaker is only valid at small distances $(<20 \mathrm{~nm})$, useful modifications are available taking care of the 'retardation' of the interaction at larger distances. The Van der Waals attraction force $F_{\text {attr }}$ between two identical spheres with radius $r_{\mathrm{p}}$ is given by:

$F_{\mathrm{attr}}=-\frac{A}{6 r_{\mathrm{p}}}\left[\frac{-4 s}{\left(s^{2}-4\right)^{2}}-\frac{4}{s^{3}}+\frac{8}{s\left(s^{2}-4\right)}\right]$

where $A$ is the so-called Hamaker constant, $r_{\mathrm{p}}$ is the radius of the spheres and $s$ is the dimensionless distance defined as the ratio of the distance between the centres and the particle radius $r_{p}$; i.e. at contact $s=2$.In Fig. 1, the non-retarded Van der Waals forces scaled by $A / 6 r_{\mathrm{p}}$ are depicted as function of the dimensionless distance $s$ revealing that the Van der Waals force diverges for small separations. However, there is a minimal distance up to which the particles can approach each other, i.e. the intermolecular distance. Both Israelachvili [15] and Hiemenz [16] proposed for this distance a value of $0.2 \mathrm{~nm}$ in the case of perfectly smooth objects. Furthermore, Fig. 1 shows that for small separations the Van der Waals attraction force decays with $(s-2)^{-2}$.

\subsection{The repulsive force caused by the overlap of electric double layers}

Most latexes used for waterborne coatings are colloidally stabilised by either electrostatic forces, due to the presence of charged groups at the particle surface, or by steric means, i.e. by repulsion between low molecular weight polymer adsorbed at the interface. Also, combinations of both mechanisms can be used. For latex particles to approach each other close enough to deform during film formation, these stabilizing forces have to be overcome.

The magnitude of the electrostatic force between two particles is governed by the surface charge density and the subsequent distribution of the electrolyte near the interface. An important quantity emerging from descriptions for the interaction of surface charges 'screened' by the electrolyte, is the Debye screening length $1 / \kappa$, which serves as an indication of the 'thickness' of the so-called electric double layer, and, in the case of a symmetrical $z: z$ electrolyte, is given by:

$\kappa^{-2}=\frac{\epsilon k T}{2 e^{2} z^{2} n_{0}}$

where $e$ is the elementary charge $\left(1.6 \times 10^{-19} \mathrm{C}\right), z$ is the valency of the electrolyte, $k$ is the Boltzmann constant $\left(1.38 \times 10^{-23} \mathrm{~J} / \mathrm{K}\right), T$ is the temperature, $\epsilon$ is the electrical 
permittivity and $n_{0}$ is the bulk concentration of the electrolyte.

When overlap of the double layers of distinct particles occurs, a repulsive force increasing the colloidal stability arises. The influence of the interparticle distance on this repulsive force has been thoroughly explained in various textbooks $[16,17]$. In order to give an estimate of the electrostatic force we will focus our attention on two extreme cases: constant surface potential and constant surface charge. Furthermore, we assume the potential to be sufficiently low, permitting the Derjaguin approximation to be used.

The force in the case of constant surface potential [17] is given by:

$F_{\mathrm{r}}^{\psi}=2 \pi \epsilon r_{\mathrm{p}} \psi_{0}^{2} \frac{\kappa \exp (-\kappa H)}{1+\exp (-\kappa H)}$

and in the case of constant surface charge [17] is given by:

$F_{\mathrm{r}}^{\alpha}=2 \pi \epsilon r_{\mathrm{p}} \psi_{0}^{2} \frac{\kappa \exp (-\kappa H)}{1-\exp (-\kappa H)}$

where $F_{\mathrm{r}}^{\psi}$ and $F_{\mathrm{r}}^{\sigma}$ are the repulsive forces in the case of constant surface potential and constant surface charge, $r_{\mathrm{p}}$ the particle radius, $\psi_{0}$ the surface potential and $H$ the surface-surface distance between the spheres. In the discussion, both expressions will be used to estimate the contribution of the repulsive forces during film formation. The implications of both expressions will be addressed in Section 3.1 .

\subsection{The capillary pressure caused by the receding of the bulk water/air interface}

The first stage of the drying of a latex film consists of the evaporation of some of the water from the latex dispersion resulting in a decrease in the average interparticle distance. This stage ends when the evaporation has proceeded to such an extent that the particles are being forced into a random packing. Since not all the water has evaporated in stage 1 , the evaporation continues in the second stage causing the water/air interface to recede from the surface of the film into the packing of particles. Due to the relatively good wetting properties of the particles this interface becomes curved with the air on the inner side of the curvature. By mechanical arguments, it can easily be shown that a pressure difference exists over a curved interface with the higher pressure on the inner side of the curvature. This implies that, in our case, the liquid pressure drops. The pressure difference across the water/air interface is the so-called capillary pressure. According to Brown [4], the capillary pressure provides the main driving force for particle deformation. This idea was elaborated by Mason [6] who provided the visualization of the capillary mechanism: the capillary force acting on the particles at the water/air interface compresses the underlying layers of close packed particles. In this section, we will derive an expression for the resulting force, both in the absence and in the presence of deformation, using assumptions more realistic than those of Mason.

The downward push exerted by the particles at the water/ air interface, i.e. by the so-called top particles, is compensated by the underlying particles exerting an upward force unto the particles at the water/air interface. Assuming face centred cubic packing (fcc), each particle at the water/air interface experiences the upward net forces of three underlying particles. In the absence of deformation the force balance for a top particle can be written in the following form ${ }^{1}$ assuming the meniscus to remain at the particle's equatorial plane:

$$
\begin{aligned}
\pi r_{\mathrm{p}}^{2}\left(P_{\mathrm{L}}-P_{\mathrm{A}}\right) & -2 \pi r_{\mathrm{p}} \gamma_{\mathrm{w} / \mathrm{a}} \cos \theta \\
& -\frac{4}{3} \pi r_{\mathrm{p}}^{3}\left(\rho_{\mathrm{s}}-\rho_{1}\right) g+\sum_{i=1}^{3} F_{\text {vertical }, \mathrm{i}}=0
\end{aligned}
$$

where $P_{\mathrm{L}}$ is the pressure in the water phase, $P_{\mathrm{A}}$ is the ambient pressure, $r_{\mathrm{p}}$ is the particle radius, $\gamma_{w / a}$ is the water/air surface tension, $\theta$ the contact angle, $\rho_{s}$ is the density of the particles, $\rho_{1}$ is the density of the liquid phase and $g$ is the gravitational acceleration. The first three terms on the left-hand side of Eq. (5) depict the downward directed force exerted by the top particle onto the underlying layer, while the fourth term depicts the sum of vertical components of the reacting forces, $F_{\text {vert, }}$, exerted by the three underlying particles. These reacting forces, directed normal to the contact area, correspond to the capillary force $F_{C}$; i.e. the force responsible for deformation. As shown in the discussion, the contribution due to the gravitational force is small compared to the contribution of the other forces and, therefore, we shall neglect the third term. The modified Eq. (5) differs from that of Mason [6] as he neglected the contribution of the surface tension forces $\left(2 \pi r_{\mathrm{p}} \gamma_{w / \mathrm{a}} \cos \theta\right)$. During deformation the shape of the particles changes from spherical to rhombic dodecahedral. This will lead to changes in the areas on which the pressures $P_{L}$ and $\mathrm{P}_{\mathrm{A}}$ act and in the circumference on which the contact forces act. Taking into account the extent of deformation $f$ as defined in Fig. 2, Eq. (5) transforms into:

$$
\begin{aligned}
F= & A(f)\left(P_{\mathrm{L}}-P_{\mathrm{A}}\right)-\left(2 \pi r_{\mathrm{p}}-C(f)\right) \gamma_{\mathrm{w} / \mathrm{a}} \cos \theta \\
& +\sum_{i=1}^{3} F_{\text {vertical } \mathrm{i}}=0
\end{aligned}
$$

where $A(f)$ is the particle's cross-section on which the capillary pressure $P_{\mathrm{L}}-P_{\mathrm{A}}$ act and $C(f)$ is the part of the particle's circumference parallel to the film/air surface that is in contact with neighbouring particles. Since with progress in deformation the analytical shape of the particles changes gradually from spherical to dodecahedral, we approximate the geometrical parameter $A(f)$ taking a linear combination

\footnotetext{
${ }^{1}$ After acceptance of the manuscript for publication it was brought to our attention that Eq. 5 is identical to the one derived by Denkov et al. [41].
} 


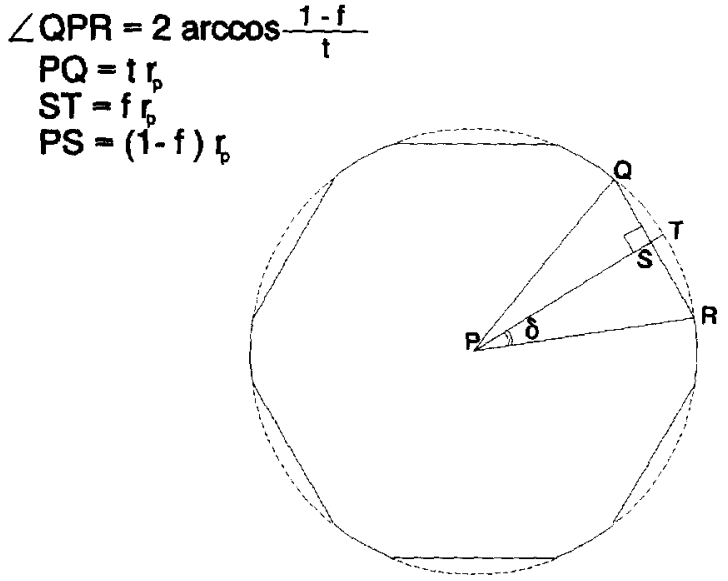

Fig. 2. The top view of the top particle being deformed.

of the spherical and dodecahedral case. For the crosssection $A(f)$ with $0 £ f £ 0.095$, we thus find:

$A(f)=v_{1}(f) A_{\text {sphere }}+v_{2}(f) A_{\text {hexagon }}$

where the coefficients $v_{l}(f)$ and $v_{2}(f)$ are given by:

$v_{1}(f)=\frac{0.095-f}{0.095} ; \quad v_{2}(f)=\frac{f}{0.095}$

From Fig. 2, it is clear that the parameter $C(f)$ is given by:

$C(f)=12 r_{\mathrm{p}} \arccos \frac{1-f}{t}$

For the two extreme values of $f, t$ attains the following values:

$t=1 \quad$ for $f=0 \quad t=\frac{2 * 0.905}{\sqrt{3}} \quad$ for $f=0.095$

As an approximation we assume $t$ to be related linearly to $f$, resulting in:

$t(f)=\frac{2 * 0.905-\sqrt{3}}{0.095 \sqrt{3}} f+1$

Accordingly, in the case of deformation Eq. (6) transforms into:

$$
\begin{aligned}
\sum_{i=1}^{3} F_{\text {vertical }, \mathrm{i}} & =\left(v_{1}(f) A_{\text {sphere }}+v_{2}(f) A_{\text {hexagon }}\right)\left(P_{\mathrm{A}}-P_{\mathrm{L}}\right) \\
& +\left(2 \pi r_{\mathrm{p}}-12 r_{\mathrm{p}} \arccos \frac{1-f}{t}\right) \gamma_{\mathrm{w} / \mathrm{a}} \cos \theta
\end{aligned}
$$

The true capillary force $F_{C}$ is the force perpendicular to the contact area formed by the top particle and the underlying particles. From Eq. (12) one can calculate the vertical component of the capillary force. The quantity $F_{C}$, according to geometrical arguments (Fig. 3), is related to $F_{\text {vert,i }}$ by:

$F_{\mathrm{C}}=\frac{1}{3} \frac{\sqrt{3}}{\sqrt{2}} \sum_{i=1}^{3} F_{\text {vertical, } \mathrm{i}}=\sqrt{\frac{3}{2}} F_{\text {vertical, } \mathrm{i}}$

Furthermore, from Eq. (12) it is clear that in order to calculate the force $F_{C}$ the magnitude of the capillary pressure,
$P_{\mathrm{A}}-P_{\mathrm{L}}$, should be given. The capillary pressure can be calculated once the shape of the curved interface is known. However, since this interface in a fcc packing is formed by three contacting spheres, the shape is too intricate to derive an exact solution. In accordance with Brown [4], we use the Haines' approximation [18] which at first seems to be a rather arbitrarily chosen estimate: according to Haines, the capillary pressure is equal to the excess pressure in an air bubble that just fits between the three contacting spheres. Using this approximation, one obtains for the capillary pressure $\Delta P_{\mathrm{C}}$ :

$\Delta P_{\mathrm{C}}=P_{\mathrm{L}}-P_{\mathrm{A}}=\frac{2 \gamma_{\mathrm{w} / \mathrm{a}} \cos \theta}{\left[\frac{2}{3} \sqrt{3}-1\right] r_{\mathrm{p}}} \approx 12.9 \frac{\gamma_{\mathrm{w} / \mathrm{a}} \cos \theta}{r_{\mathrm{p}}}$

where $\gamma_{w / a}$ is the water/air surface tension and $\theta$ is the contact angle of the water/air interface and the particles. Lin and Meier [19,20] rightly pointed out that this approximation has no sound physical background. Although this is certainly true, the theoretical work done by Princen [2123] and the experiments performed by Mason and Morrow [24] show that this approximation leads to errors of less than $10 \%$; i.e. the numerical factor in Eq. (14) being 11.07 instead of 12.9 .

Combining Eq. (6), (13) and (14) enables one to estimate the magnitude of the capillary force caused by the receding water/air interface:

$\frac{F_{\mathrm{C}}}{\gamma_{\mathrm{w} / \mathrm{a}} r_{\mathrm{p}} \cos \theta}=\frac{1}{3} \sqrt{\frac{3}{2}}\left(12.9 \frac{A(f)}{r_{\mathrm{p}}^{2}}+2 \pi-\frac{C(f)}{r_{\mathrm{p}}}\right)$

It is interesting to compare our result with Mason's original result [6] derived on slightly different argumentation:

$\frac{F_{C}}{\gamma_{\mathrm{w} / \mathrm{a}} r_{\mathrm{p}} \cos \theta}=\frac{2 \sqrt{2}(1-f)^{2}}{\frac{2}{3} \sqrt{3}-1}$

Both equations are depicted in Fig. 4. The obvious differences between Eqs. (15) and (16) are caused by the fact that (a) Mason neglected the contribution due to the surface tension forces, and (b) Mason assumed the particle's

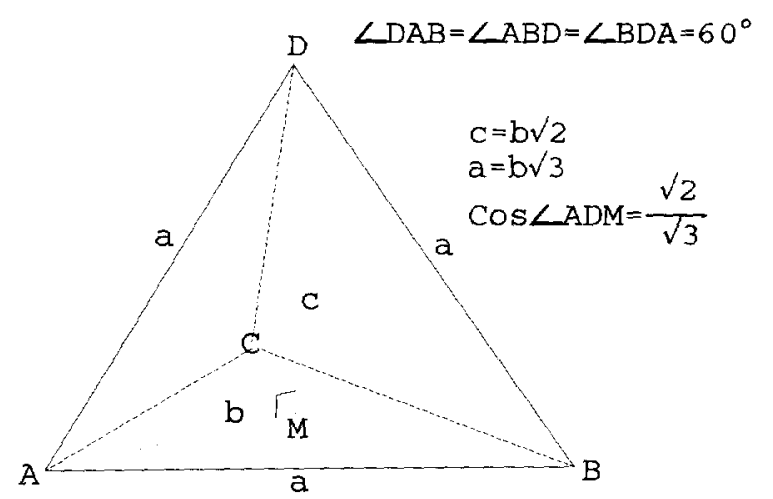

Fig. 3. A particle in point $D$ exerts a force upon the three underlying particles ( $\mathrm{A}, \mathrm{B}$, and $\mathrm{C}$ ), together forming a perfect tetrahedron (M: perpendicular projection of $\mathrm{D}$ on triangle $\mathrm{ABC}$ ). 


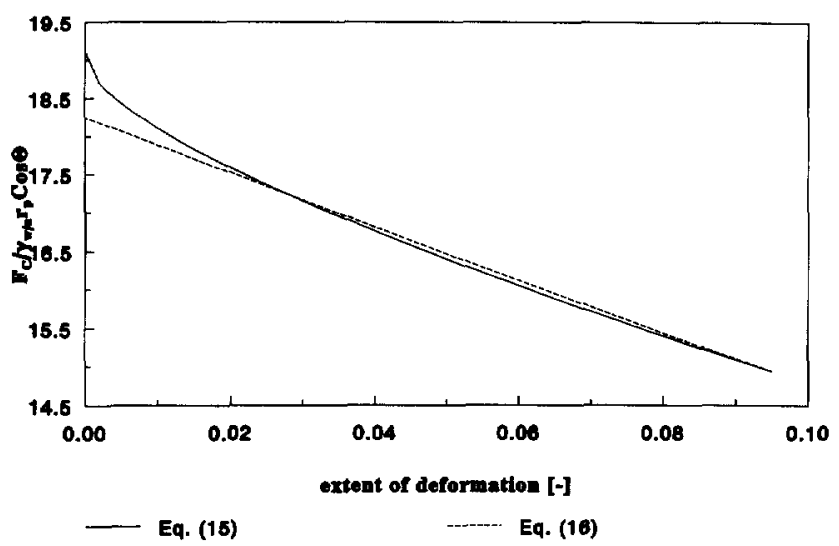

Fig. 4. A comparison between the capillary force $F_{\mathrm{c}}$ as obtained by Mason [6], Eq. (16), and as calculated in this paper, Eq. (15).

cross section to be hexagonal resulting in a larger cross section at $f=0$. Note that both equations lead to the same results for complete deformation, i.e. at $f=0.095$, since in the case of complete deformation, the contribution of the surface tension forces vanishes and the cross-section transgresses into a hexagon.

\subsection{The capillary pressure caused by liquid bridges between particles}

After the water/air interface has reached the substrate surface, some residual water will remain at the contacts between adjoining particles forming structures which will be denoted as liquid bridges (Fig. 5). These bridges are in thermodynamic equilibrium with the water vapour present in the film. Depending on the curvature of the liquid bridges the pressure in the bridge will tend to press the particles together or even to push them apart. The pressure difference between the outside and the inside of the bridge is given by:

$$
\Delta P_{\mathrm{C}}=\gamma_{\mathrm{w} / \mathrm{a}}\left(r_{1}^{-1}+r_{2}^{-1}\right)
$$

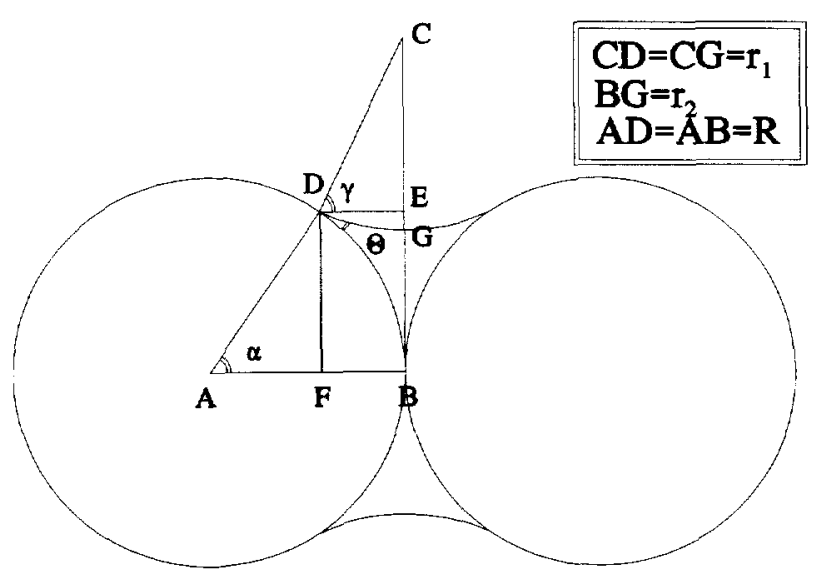

Fig. 5. The liquid bridge between two similar particles.

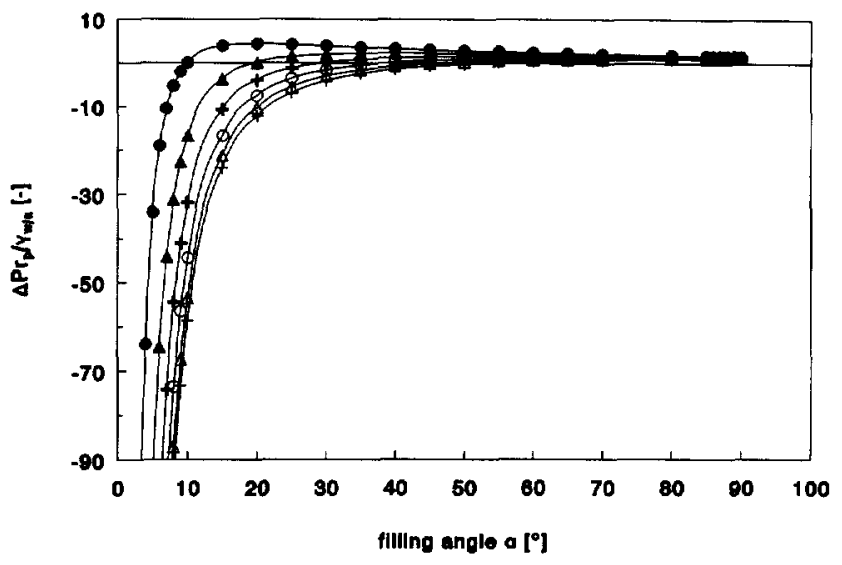

Fig. 6. Pressure difference due to a liquid bridge between similar spheres as a function of the filling angle, for various contact angles $\left(+: 0^{\circ} ; \Delta: 15^{\circ}\right.$; O: $30^{\circ} ;+: 45^{\circ}$ ^: $60^{\circ} ;: 75^{\circ}$ ).

where $r_{1}$ and $r_{2}$ are the radii of the liquid bridge depicted in Fig. 5. Note that negative radii of curvature correspond to concave surfaces, while positive radii correspond to convex surfaces. Geometric considerations provide the link between the radii $r_{1}$ and $r_{2}$, the contact angle $\theta$ and the filling angle $\alpha$ :

$r_{1}=-r_{\mathrm{p}} \frac{1-\cos \alpha}{\cos (\alpha+\theta)}$

$r_{2}=r_{\mathrm{p}}\left[\sin \alpha+\frac{1-\cos \alpha}{\cos (\alpha+\theta)}(\sin (\alpha+\theta)-1)\right]$

This set of equations enables us to calculate the pressure inside liquid bridges as a function of the filling angle $\alpha$ (Fig. 6). However, it is much more revealing to consider the force instead of the pressure difference resulting from these bridges. The force is provided by the pressure inside the liquid bridge pulling or pushing the spheres apart and by the water/air surface tension pulling the spheres together. Considering the plane of symmetry between the two particles, line $\mathrm{BC}$ in Fig. 5, a force balance can be constructed [25]:

$F_{\mathrm{C}}=\Delta P_{\mathrm{C}} \pi r_{2}^{2}-2 \pi r_{2} \gamma_{\mathrm{w} / \mathrm{a}}$

where $F_{\mathrm{C}}$ is the contact force pushing the particles apart, $r_{2}$ is the radius defined in Fig. 5 and $\gamma_{w / a}$ is the water/air surface tension. A negative capillary force, $F_{\mathrm{C}}$, corresponds to the case that the two spheres are pulled together. Fig. 7 reveals that in the case of large contact angles, e.g. hydrophobic materials, the force can even result in a repulsion between the spheres. The filling angle $a$ is a very awkward parameter as it can not be controlled properly. The amount of water forming the liquid bridge will rather depend on the relative humidity of the surrounding air; a low relative humidity, RH, will result in a small filling angle and, therefore, in a large attractive force between the spheres. The relative humidity is related to curvature of the liquid bridge by the Kelvin equation [17]: 


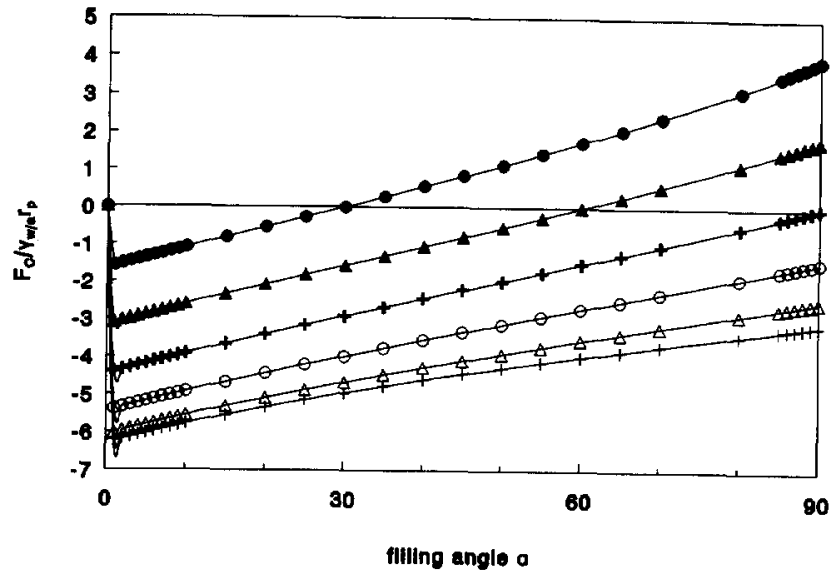

Fig. 7. The force due to a liquid bridge as a function of the filling angle, for various contact angles $\left(+: 0^{\circ} ; \Delta: 15^{\circ} ; 0: 30^{\circ} ;+: 45^{\circ} ; \mathbf{\Lambda}: 60^{\circ} ; 75^{\circ}\right)$.

$\ln [R H]=\frac{\gamma_{\mathrm{w} / \mathrm{a}} V}{R T}\left[\frac{1}{r_{1}}+\frac{1}{r_{2}}\right]$

where $\gamma_{w / a}$ is the water/air surface tension, $V$ is the molar volume of liquid water, $R$ is the gas constant and $T$ the temperature. Using the Kelvin equation we can calculate the force as a function of the relative humidity. Fig. 8 reveals that the relative humidity has little influence on the capillary force; only when the humidity is close to 1 , does the force change considerably in magnitude. This is an important conclusion: a latex paint will dry at practically all humidities as long as it is not wetted directly by e.g. rain or condensation. In contrast to the particle radius, the contact angle has a major influence on the magnitude of the dimensionless force $F_{\mathrm{C}} / \gamma_{w / a} r_{\mathrm{p}}$ (Fig. 9).

Up till now, we have mainly paid attention to the force between two undeformable spherical particles, originating from the presence of a liquid bridge. Since, depending on their mechanical behaviour, the particles will deform under

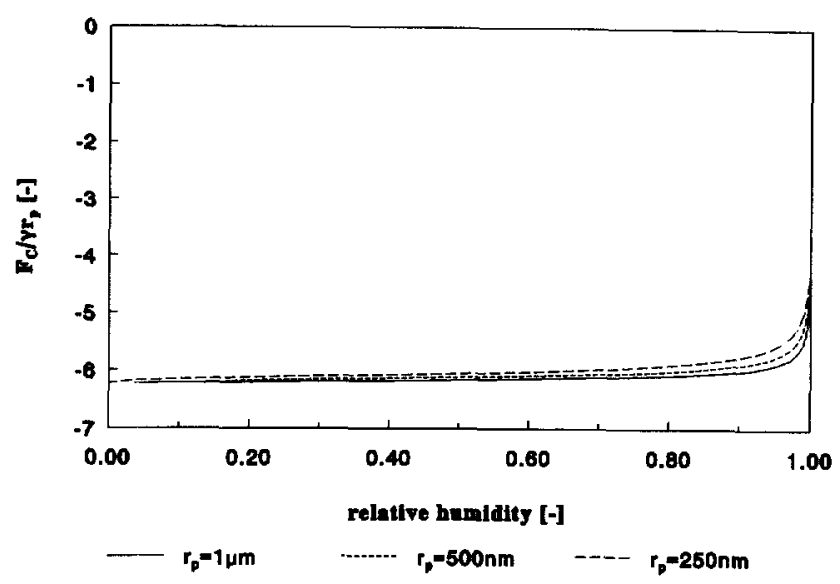

Fig. 8. The force due to a liquid bridge as a function of the relative humidity, for various particle radii $(T=298 \mathrm{~K} ; \gamma=0.070 \mathrm{~N} / \mathrm{m}$; $R=8.314 \mathrm{~J} / \mathrm{mol} \mathrm{K} ; V=1.8 e^{-5} \mathrm{~m}^{3} / \mathrm{mol}$ ).

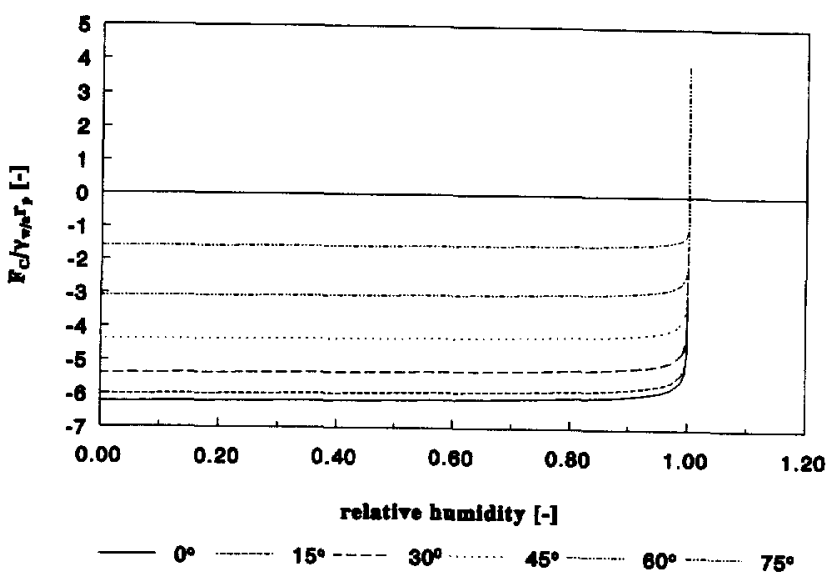

Fig. 9. The force due to a liquid bridge as a function of the relative humidity, for various contact angles $\left(r_{\mathrm{p}}+1 \mu \mathrm{m} ; \gamma_{w t a}=0.070 \mathrm{~N} / \mathrm{m}\right.$; $T=298 \mathrm{~K}$ ).

the influence of that force, the extent of particle deformation must be taken into account. This may be incorporated by assuming the form of the particle surface outside the contact area to be purely spherical. As deformation flattens the contacting part of the sphere, volume conservation dictates an increase in the particle radius with progress in deformation. The increase in the radius can be calculated using the following equation:

$\frac{1}{3} \pi r_{\mathrm{p}}^{3}\left(2+3 \cos \delta-\cos ^{3} \delta\right)=\frac{4 \pi}{3} r_{\mathrm{p}, 0}^{3}$

where $r_{p, 0}$ is the radius before deformation and $\delta$ is the deformation angle defined in Fig. 2. Under these assumptions, we can again calculate the radii of liquid bridges, but, in contrast to the case of rigid spheres, the radii are now a function of both the filling angle $\alpha$ and the extent of deformation $f$ :

$r_{1}=-r_{\mathrm{p}} \frac{1-\cos \alpha-f}{\cos \alpha}$

$r_{2}=r_{\mathrm{p}}\left[\sin \alpha-\frac{1-\cos \alpha-f}{\cos \alpha}(1-\sin \alpha)\right]$

The formation of a contact area also influences the area on which the liquid pressure acts; the liquid area in Eq. (20) should be corrected for the contact area created. This leads to:

$F_{\mathrm{C}}=\Delta P_{\mathrm{C}}\left(\pi r_{2}^{2}-2 \pi f r_{\mathrm{p}}^{2}\right)-2 \pi r_{2} \gamma_{\mathrm{w} / \mathrm{a}}$

This equation provides a method to incorporate the extent of deformation into the model of liquid bridges. In Fig. 10, calculations similar to those in Fig. 8 are depicted for revealing the influence of the extent of deformation on the magnitude of the force. From this we may conclude that the force due to the presence of a liquid bridge is nearly constant during deformation, i.e. the influence of the extent of deformation is negligible. The magnitude of the force is largely determined by the particle radius and 


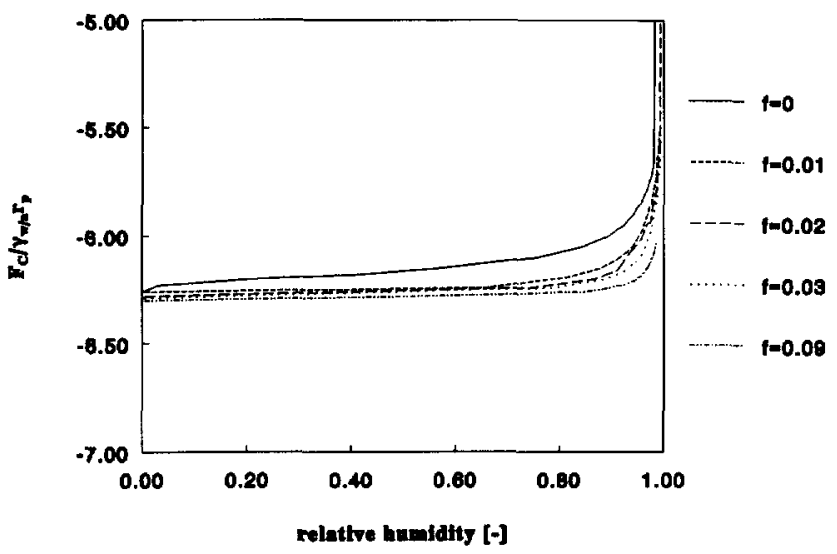

Fig. 10. The force due to a liquid bridge as a function of the relative humidity, for various degrees of deformation $\left(r_{\mathrm{p}}=1 \mu \mathrm{m} ; \gamma_{\mathrm{w} / \mathrm{a}}=0.070\right.$ $\mathrm{N} / \mathrm{m} ; T=2998 \mathrm{~K}$ ).

the contact angle. In the case of zero contact angle and for a wide range of humidities, the force can be given by:

$F_{\mathrm{C}}=6.2 \gamma_{\mathrm{w} / \mathrm{a}} r_{\mathrm{p}}$

\subsection{The force necessary to deform the particles}

Good final film properties, like good mechanical strength or low water permeability, require the closure of the voids present at the onset of particle deformation. This closure is accompanied by the shrinkage of the film; i.e. a reduction of the film volume by $26 \%$. The particle deformation as addressed in the following sections assumes isotropic shrinkage on a macroscopic scale, i.e. the interparticle distances decrease uniformly in all directions, resulting in a reduction of the centre-to-contact area distance by 0.095 times the initial particle radius (the reduction corresponds to the line $S T=f r_{\mathrm{p}}$ in Fig. 2). Due to the stress conditions at the film/substrate interface, shrinkage along the film/substrate interface, a prerequisite for isotropic shrinkage, may, however, be inhibited resulting in tensile stresses within the film and maybe even in cracks. Therefore, uniaxial shrinkage often occurs whereby the interparticle distances in the plane parallel to the film surface remain constant while the distances in the normal direction reduce by $(1-{ } 0.74)=0.140$ times the initial particle radius. Although physically more realistic, uniaxial shrinkage is more difficult to describe theoretically. Therefore, we will restrict ourselves to isotropic shrinkage.

The ease with which the particle may deform to the extent needed for closure of the voids, is governed by the mechanical behaviour of the particles. Thus, a model able to describe the mechanical behaviour is of pivotal importance for finding a theoretical description of film formation. In this section, we will discuss the consequences of the application of three different models to the deformation of polymer particles during film formation; (i) the Hertz description of the deformation of non-attracting elastic bodies, (ii) the
JKR description of the deformation of attracting, elastic bodies, and (iii) the visco-elastic description by Yang for non-attracting bodies. These models all yield an expression for the radius of the contact area formed when two spheres are pressed together. One can define successful deformation along two different routes; successful deformation is achieved either (i) when the radius, $a$, of the contact area reaches beyond a certain minimal value, this minimal value to be specified later, or (ii) when the displacement, $w_{0}$, exceeds the value of 0.095 -times the particle radius. For a consistent model, these criterions should yield the same result. The expressions for the contact area and the displacement $w_{0}$ within the different models are as follows.

\subsubsection{Hertz equation for elastic bodies $[26,27]$ :}

$a^{3}=\frac{3}{8}(1-\nu) \frac{r_{\mathrm{p}} F}{G}$

$w_{0}=f r_{\mathrm{p}}=\frac{a^{2}}{r_{\mathrm{p}}} \Leftrightarrow a^{2}=w_{0} r_{\mathrm{p}}$

where $\nu$ is the Poisson ratio, $G$ is the shear modulus and $F$ is the force responsible for the creation of the contact area.

2.6.2. JKR equation for attracting, elastic bodies $[8,28,29]$ :

$a^{3}=\frac{3}{8}(1-\nu) \frac{r_{\mathrm{p}}}{G} F^{+}$

$w_{0}=\frac{3}{8} \frac{F^{+}}{a} \frac{(1-\nu)}{G}$

where $F^{+}$is given by:

$F^{+}=F+3 r_{\mathrm{p}} \pi \gamma_{\mathrm{sv}}+\sqrt{6 \pi r_{\mathrm{p}} \gamma_{\mathrm{sv}} F+\left(3 \pi r_{\mathrm{p}} \gamma_{\mathrm{sv}}\right)^{2}}$

2.6.3. Yang equation for non-attracting, visco-elastic bodies [30]:

$a^{3}(t)=\frac{3 r_{\mathrm{p}}}{8} \int_{0}^{t} 2 k(t-\tau) \frac{\partial F(\tau)}{\partial \tau} \mathrm{d} t$

where $\tau$ is the time dependent integration variable and $k(t-\tau)$ is a function describing the visco-elastic behaviour of the material and can be obtained by solving the following integral equation:

$2 G *(6 K+2 G) * k=3 K+4 G$

where $G$ and $K$ are the time dependant shear and compressibility moduli and $*$ denotes the convolution operation like in:

$\phi * \psi=\int_{0}^{t} \phi(t-\tau) \frac{\mathrm{d}}{\mathrm{d} \tau} \psi(\tau) \mathrm{d} \tau$ 
Table 1

The Van der Waals force $(\mathrm{N})$ between two identical spherical particles at various distances between the particles $\left(A=1.05 \times 10^{-20} \mathrm{~J}\right)$

\begin{tabular}{|c|c|c|c|c|c|c|}
\hline \multirow{2}{*}{$\begin{array}{l}\text { Particle } \\
\text { radius (nm) }\end{array}$} & \multicolumn{6}{|c|}{ Distance between the particles (nm) } \\
\hline & 50 & 10 & 5 & 1 & 05 & 0.2 \\
\hline 125 & $2.1 \times 10^{-14}$ & $9.4 \times 10^{-13}$ & $4.0 \times 10^{-12}$ & $1.1 \times 10^{-10}$ & $4.3 \times 10^{-10}$ & $2.7 \times 10^{-9}$ \\
\hline 250 & $6.0 \times 10^{-14}$ & $2.0 \times 10^{-12}$ & $8.4 \times 10^{-12}$ & $2.2 \times 10^{-10}$ & $8.7 \times 10^{-10}$ & $5.5 \times 10^{-9}$ \\
\hline 500 & $1.4 \times 10^{-13}$ & $4.2 \times 10^{-12}$ & $1.7 \times 10^{-11}$ & $4.4 \times 10^{-10}$ & $1.8 \times 10^{-9}$ & $1.1 \times 10^{-8}$ \\
\hline
\end{tabular}

The core of most attempts to model film formation consists of combining one of these three set of equations with an expression for the driving force for film formation. The historically first attempt resulted in the Brown-Mason model in which Eqs. (16) and (28) were combined.

\section{Results and discussion}

\subsection{Magnitude of the forces at contact}

In the previous section, equations were given for the various forces occurring during film formation. In Table 1, the magnitude of the Van der Waals force is listed as function of both the interparticle distance $H=a-2 r_{\mathrm{p}}$ and the radius $r_{\mathrm{p}}$ of the polymer particles. The Van der Waals contribution is calculated by using the Hamaker expression, Eq. (1), in the case of two identical, spherical particles. The Hamaker constant used for these calculations is in accordance with values normally quoted in literature; e.g. compare the Hamaker constant given by Lyklema [31] for PMA in water $1.05 \times 10^{-20} \mathrm{~J}$. Table 1 shows that the contribution of the Van der Waals force increases sharply at very small separations indicating that the Van der Waals force may be of considerable influence at very small separations. However, one might give an upper limit for the Van der Waals force assuming the closest distance of approach to be $0.2 \mathrm{~nm}$ as discussed in Section 2.2. This leads to a Van der Waals force of $5.5 \times 10^{-9} \mathrm{~N}$ in the case of $250 \mathrm{~nm}$ particles. Note that $\mathrm{Eq}$. (1) represents the Van der Waals force in the unretarded

Table 2

Repulsive electrical force between particles at various distances in a $10^{-3}$ M 1:1 electrolyte $\left(\kappa^{-1} 9.6 \mathrm{~nm} ; r^{p}=250 \mathrm{~nm} ; \psi_{0}=-70 \mathrm{mV}\right)$

\begin{tabular}{lll}
\hline $\begin{array}{l}\text { Distance between } \\
\text { particles }(\mathrm{nm})\end{array}$ & $\begin{array}{l}\text { Repulsive force due to the overlap of } \\
\text { double layers }(\mathrm{N})\end{array}$ \\
\cline { 2 - 3 } & Constant potential & Constant charge \\
\hline 50 & $3.1 \times 10^{-12}$ & $3.1 \times 10^{-12}$ \\
10 & $1.5 \times 10^{-10}$ & $3.1 \times 10^{-10}$ \\
5 & $2.1 \times 10^{-10}$ & $8.3 \times 10^{-10}$ \\
1 & $2.7 \times 10^{-10}$ & $5.2 \times 10^{-9}$ \\
0.5 & $2.8 \times 10^{-10}$ & $1.1 \times 10^{-8}$ \\
0.2 & $2.8 \times 10^{-10}$ & $2.7 \times 10^{-8}$ \\
\hline
\end{tabular}

mode. At separations larger than $25 \mathrm{~nm}$ the correlation between the induced dipoles becomes less effective, leading to a faster decrease of the interaction potential with increasing distance than given by Eq. (1) [32].

In Table 2, values are listed for the repulsive force due to diffuse double layers between two spherical particles with a radius $r_{\mathrm{p}}=250 \mathrm{~nm}$ and a surface potential $\psi_{0}=-70 \mathrm{mV}$ in the presence of a $10^{-3} \mathrm{M} 1: 1$ electrolyte. The calculations have been performed for the case of constant potential and constant charge using Eqs. (3) and (4). Assuming again that the smallest distance of approach is $0.2 \mathrm{~nm}$, the repulsive force amounts to $2.8 \times 10^{-10} \mathrm{~N}$ under constant potential conditions and to $2.7 \times 10^{-8} \mathrm{~N}$ under constant charge conditions. As the particles come into contact, the repulsive force under constant charge conditions diverges. Russel et al. [33] attributed this effect to the limitation on the Derjaguin approximation. The diverging character of the constant charge condition has been one of the reasons constant potential is viewed as being the more realistic one and is therefore the one most frequently used in simulations [34]. In the calculations to come, we will also assume constant potential conditions.

During evaporation the electrolyte concentration increases. From Table 3 one may observe the influence of the electrolyte concentration on electrostatic repulsion. At large separations the repulsive force is decreasing rapidly when raising the electrolyte concentration, while at low separations the repulsive forces are larger in the case of higher electrolyte concentration.

By means of our improved Brown-Mason equation, Eq. (15), the force generated by the bulk water/air interface receding through the particle matrix, can be calculated. The results of these calculations are listed in Table 4, revealing that the capillary force is in most cases considerably larger than both the Van der Waals force and the electrostatic repulsion; e.g. the capillary force in the case of 250 $\mathrm{nm}$ particles, in the absence of any deformation, amounts to $2.45 \times 10^{-7} \mathrm{~N}$.

In Table 5, the results regarding the force due to the presence of liquid bridges are listed showing that this force is of the same order of magnitude as the force generated by the bulk water/air interface receding through the film; e.g. in the case of $250 \mathrm{~nm}$ particles, the capillary force due to the presence of liquid bridges amounts to 
Table 3

Repulsive electrical force between spherical particles at different electrolyte concentrations $\left(r_{\mathrm{p}}=250 \mathrm{~nm} ; \psi_{0}=-70 \mathrm{mV} ; z=1\right)$

\begin{tabular}{llllll}
\hline $\begin{array}{l}\text { Distance between } \\
\text { particles (nm) }\end{array}$ & \multicolumn{5}{l}{ Repulsive force due to the overlap of double layers at different $1: 1$ electrolyte concentration (N) } \\
\cline { 2 - 6 } & $1 \times 10^{-5} \mathrm{M}$ & $1 \times 10^{-4} \mathrm{M}$ & $1 \times 10^{-3} \mathrm{M}$ & $1 \times 10^{-2} \mathrm{M}$ & $1 \times 10^{-1} \mathrm{M}$ \\
\hline 50 & $2.1 \times 10^{-11}$ & $2.9 \times 10^{-11}$ & $3.2 \times 10^{-12}$ & $1.4 \times 10^{-16}$ & $2.1 \times 10^{-31}$ \\
10 & $2.7 \times 10^{-11}$ & $7.5 \times 10^{-11}$ & $1.5 \times 10^{-10}$ & $6.6 \times 10^{-11}$ & $1.8 \times 10^{-13}$ \\
5 & $2.8 \times 10^{-11}$ & $8.2 \times 10^{-11}$ & $2.1 \times 10^{-10}$ & $2.9 \times 10^{-10}$ & $3.2 \times 10^{-11}$ \\
1 & $2.8 \times 10^{-11}$ & $8.8 \times 10^{-11}$ & $2.7 \times 10^{-10}$ & $7.5 \times 10^{-10}$ & $1.5 \times 10^{-9}$ \\
0.5 & $2.8 \times 10^{-11}$ & $8.9 \times 10^{-11}$ & $2.8 \times 10^{-10}$ & $8.2 \times 10^{-10}$ & $2.1 \times 10^{-9}$ \\
0.2 & $2.8 \times 10^{-11}$ & $8.9 \times 10^{-11}$ & $2.8 \times 10^{-10}$ & $8.6 \times 10^{-10}$ & $2.5 \times 10^{-9}$ \\
\hline
\end{tabular}

$1.09 \times 10^{-7} \mathrm{~N}$ with zero contact angle and no deformation. The influence of the air humidity and of the extent of deformation on the force have been explained in Section 2.6.

Estimates of all forces relevant to deformation, in case of two $250 \mathrm{~nm}$ spheres, are collected in Table 6. Among the forces promoting deformation, the force generated by the receding water/air interface and the force generated by the liquid bridges are the largest. Their order of magnitude, i.e. $10^{-7} \mathrm{~N}$, is in good agreement with the value needed for successful deformation. At contact, it is questionable whether the Van der Waals force may not give a significant contribution although, assuming a value of $0.2 \mathrm{~nm}$ as the closest distance of approach, the Van der Waals contribution is more than a factor of 20 smaller than both capillary forces. A sound incorporation of the Van der Waals force in the film formation models can be obtained either by combining the expressions for both the Van der Waals force and the capillary force or by using the JKR theory in which the Van der Waals forces are automatically incorporated through the interfacial energy.

On the particle's response part, the particles can be viewed to be either elastic or visco-elastic. Modelling can be achieved using different combinations of models for driving force and particle's response. A number of them are discussed in the next sections. These are listed in Table 7 together with the section which deals with the corresponding model.

\subsection{Theoretical descriptions of particle deformation based on the Hertz equations}

As previously remarked, the first theoretical descriptions of the film formation process were based on the assumption that the polymer particles can be viewed as being purely elastic $[4,6]$. Therefore, one could proceed from the Hertz equations $[26,27]$ to model the particle's response to deformation; by combining Eqs. (27) and (28) one obtains an expression for the shear modulus as a function of the extent of deformation $f$ and the applied force $F$ :

$G \leq \frac{3}{8}(1-\nu) \frac{F}{f \sqrt{f} r_{\mathrm{p}}^{2}}$

Inserting the value of 0.095 for the extent of deformation, one obtains an expression linking the maximal shear modulus at which successful deformation occurs and the applied force.

The Brown-Mason model is based on the assumption that the driving force is provided by the receding of the bulk water/air interface through the particle matrix. Combining Eqs. (16) and (34) leads to the following expression, under the assumption that the Poisson ratio equals 0.5 :

$G<95.88 \frac{\gamma_{\mathrm{w} / \mathrm{a}}}{r_{\mathrm{p}}}$

Note that the Poisson ratio, in film formation literature traditionally taken to be 0.5 corresponds to a incompressible material, while experimentally determined values are usually beneath this value; e.g. Van Krevelen [35] quotes a value of 0.40 in the case of poly methyl methacrylate.

Apart from the force due to a receding water/air interface, the force generated by the presence of liquid bridges is also large enough to cause deformation (Table 6). From Section 2.4 , it is clear that this force is nearly constant during particle deformation; i.e. the magnitude of this force is not changed considerably by changes in the extent of deformation or air humidity. In the case of a zero degree contact

Table 4

The capillary force $F_{\mathrm{c}}$ due to the receding W/A interface as obtained by Eq. (15) $\left(\gamma_{w / a}=0.070 \mathrm{~N} / \mathrm{m} ; \theta=0^{\circ}\right)$

\begin{tabular}{|c|c|c|c|c|c|c|}
\hline \multirow[t]{2}{*}{ Radius (nm) } & \multicolumn{6}{|c|}{ Extent of deformation $f(-)$} \\
\hline & 0 & 0.02 & 0.04 & 0.06 & 0.08 & 0.095 \\
\hline 125 & $1.67 \times 10^{-7}$ & $1.76 \times 10^{-7}$ & $1.47 \times 10^{-7}$ & $1.40 \times 10^{-7}$ & $1.35 \times 10^{-7}$ & $1.31 \times 10^{-7}$ \\
\hline 250 & $3.34 \times 10^{-7}$ & $3.08 \times 10^{-7}$ & $2.93 \times 10^{-7}$ & $2.81 \times 10^{-7}$ & $2.69 \times 10^{-7}$ & $2.62 \times 10^{-7}$ \\
\hline 500 & $6.69 \times 10^{-7}$ & $6.16 \times 10^{-7}$ & $5.87 \times 10^{-7}$ & $5.62 \times 10^{-7}$ & $5.39 \times 10^{-7}$ & $5.23 \times 10^{-7}$ \\
\hline
\end{tabular}


Table 5

The capillary force $F(\mathrm{~N})$ due to the presence of liquid bridges between rigid particles as obtained by Eq. (20)

\begin{tabular}{llllll}
\hline Radius $(\mathrm{nm})$ & \multicolumn{1}{l}{ Contact angle } & & & \\
\cline { 2 - 5 } & $0^{\circ}$ & $30^{\circ}$ & $45^{\circ}$ & $60^{\circ}$ & $75^{\circ}$ \\
\hline 125 & $5.45 \times 10^{-8}$ & $4.72 \times 10^{-8}$ & $3.85 \times 10^{-8}$ & $2.73 \times 10^{-8}$ & $1.41 \times 10^{-8}$ \\
250 & $1.09 \times 10^{-7}$ & $9.44 \times 10^{-8}$ & $7.71 \times 10^{-8}$ & $5.45 \times 10^{-8}$ & $2.82 \times 10^{-8}$ \\
500 & $2.18 \times 10^{-7}$ & $1.89 \times 10^{-7}$ & $1.54 \times 10^{-8}$ & $1.09 \times 10^{-7}$ & $5.64 \times 10^{-8}$ \\
\hline
\end{tabular}

angle, the force generated by liquid bridges may be described as:

$F_{\mathrm{C}}=6.2 \gamma_{\mathrm{w} / \mathrm{a}} r_{\mathrm{p}}$

Combining Eqs. (35) and (36) and using the same value for the Poisson ratio results in the following criterion for the shear modulus:

$G<39.89 \frac{\gamma_{\mathrm{w} / \mathrm{a}}}{r_{\mathrm{p}}}$

It should be noted that although the pre-factor in Eq. (38) is smaller than the one in Eq. (36), the latter mechanism also offers the possibility of delayed film formation, since the films do no longer have to be 'wet'. If one would dry a latex film below MFFT so that no particle deformation will occur and if one subsequently raises the temperature till above the MFFT, particle deformation through the mechanism underlying Eq. (36) can not be achieved, because there is no receding water/air interface generating the necessary capillary force. However, due to capillary condensation there is always some residual water left between wetting polymer particles, leading to deformation if the temperature is raised till above the 'dry' MFFT. We may therefore conclude that there may be two MFFTs: one 'wet' MFFT for particle deformation in the presence of a receding

Table 6

Overview of the estimates of the various forces operative during particle deformation

\begin{tabular}{|c|c|}
\hline & Estimate force $(\mathrm{N})$ \\
\hline $\begin{array}{l}\text { Gravitational force on a particle }\left(g=9.81 \mathrm{M} / \mathrm{s}^{2}\right. \\
\left.\quad r_{\mathrm{p}}=250 \mathrm{~nm} ; \Delta \varrho=100 \mathrm{~kg} / \mathrm{m}^{3}\right)\end{array}$ & $6.4 \times 10^{-17}$ \\
\hline $\begin{array}{l}\text { Van der Waals force (separation: } 5 \mathrm{~nm} ; r_{\mathrm{p}}= \\
250 \mathrm{~nm} ; A=1.05 \times 10^{-20} \mathrm{~J} \text { ) }\end{array}$ & $8.4 \times 10^{-12}$ \\
\hline $\begin{array}{l}\text { Van der Waals force (separation: } 0.2 \mathrm{~nm} ; r^{p}= \\
250 \mathrm{~nm} ; A=1.05 \times 10^{-20} \mathrm{~J} \text { ) }\end{array}$ & $5.5 \times 10^{-9}$ \\
\hline $\begin{array}{l}\text { Electrostatic repulsion (const. potential; contact; } \\
r_{\mathrm{p}}=250 \mathrm{~nm} ; \psi=-70 \mathrm{mV} ; 10^{-3} \mathrm{M} \text { ) }\end{array}$ & $2.8 \times 10^{-10}$ \\
\hline $\begin{array}{l}\text { Capillary force due to receding water/air interface } \\
\qquad\left(r_{\mathrm{p}}=250 \mathrm{~nm} ; \gamma_{\mathrm{w} / \mathrm{a}}=0.07 \mathrm{~N} / \mathrm{m} ; f=0.095 ; \theta=0^{\circ}\right)\end{array}$ & $2.6 \times 10^{-7}$ \\
\hline $\begin{array}{l}\text { Capillary force due to liquid bridges }\left(r_{\mathrm{p}}=\right. \\
\left.250 \mathrm{~nm} ; \gamma_{\mathrm{w} / \mathrm{a}}=0.07 \mathrm{~N} / \mathrm{m} ; \theta=0^{\circ}\right)\end{array}$ & $1.1 \times 10^{-7}$ \\
\hline $\begin{array}{l}\text { Force necessary for deformation using Hertz } \\
\text { equation }\left(r_{\mathrm{p}}=250 \mathrm{~nm} ; G=10^{7} \mathrm{~Pa}\right)\end{array}$ & $1.0 \times 10^{-7}$ \\
\hline
\end{tabular}

A typical value for the elastic modulus of a polymer material close to the glass transition point as given by Van Krevelen [35]. water/air interface and one 'dry' MFFT for particle deformation in the absence of a receding water/air interface and at which particle deformation occurs due to liquid bridges. Experiments performed by Sperry et al. [36] have shown the existence of both a 'wet' and a 'dry' MFFT. From Eqs. (36) and (38), it is clear that the 'wet' MFFT is always below the 'dry' MFFT. In general, the 'wet' MFFT is experimentally determined to be close to the glass transition temperature, $T_{\mathrm{g}}$, of the polymer particles involved. Because of the dramatic decrease in the shear modulus in this region, it could be that it is experimentally impossible to discern between the 'wet' and 'dry'MFFT. Additionally, it is still not clear whether the difference in MFFT is caused by different deformation mechanisms [37] or by the 'softening' of the polymer particles in the presence of water (hydroplasticization) [36,38,39].

It should be noted that both Eqs. (36) and (38) predict a linear relation for the elastic modulus and the reciprocal particle radius. This does not conform to the experimental findings by Eckersley et al. [40]. There is not as yet a satisfactory explanation for this effect.

\subsection{Theoretical descriptions of particle deformation based on the JKR equations}

The extension of the Hertz theory for elastic bodies in order to account for Van der Waals forces resulted in the JKR theory $[28,29]$ for 'sticky' solids. Note that in the absence of Van der Waals forces, i.e. when the interfacial energy equals zero, Eq. (29) transforms into the Hertz solution. Combining the JKR equation with the Eq. (16), i.e. the capillary force due to a receding water/air interface, renders the following criterion for particle deformation:

Table 7

A schematic representation of the different combinations of driven force and mechanical behaviour and the corresponding sections of this paper

\begin{tabular}{lll}
\hline & Elastic & $\begin{array}{l}\text { Visco- } \\
\text { elastic }\end{array}$ \\
\hline Receding water/air interface & 3.2 & - \\
Receding water/air interface + & 3.3 & - \\
$\quad$ Van der Waals forces & 3.2 & 3.4 \\
Liquid bridges & 3.3 & - \\
\hline
\end{tabular}




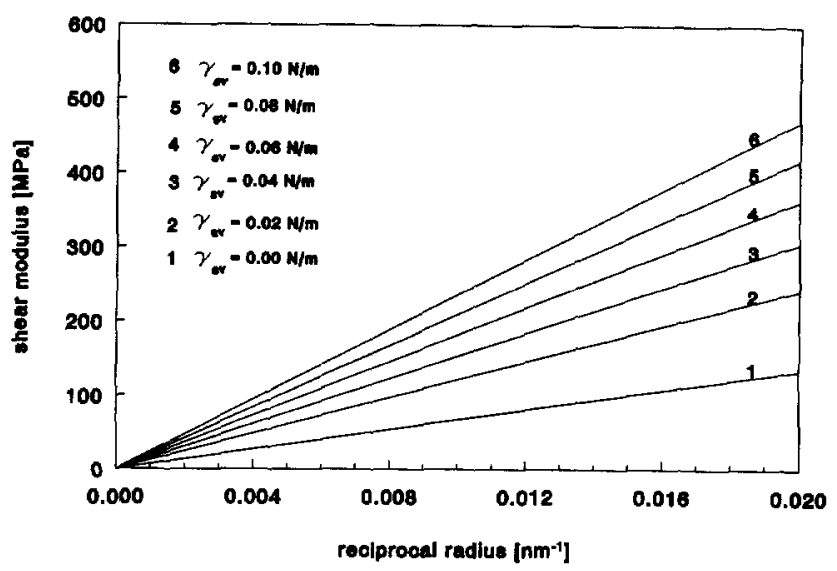

Fig. 11. The criterion for successful particle deformation derived by combining the JKR equations and ( for the capillary force $\left(\nu=0.5 ; \gamma_{\mathrm{w} / \mathrm{a}}=0.07\right.$ $\mathrm{N} / \mathrm{m}$ ).

$G \leq \frac{3}{8}(1-\nu) \frac{F_{\mathrm{C}}+3 \pi \gamma_{\mathrm{sv}}+\sqrt{6 \pi r_{\mathrm{p}} \gamma_{\mathrm{sv}} F_{\mathrm{C}}+\left(3 \pi r_{\mathrm{p}} \gamma_{\mathrm{sv}}\right)^{2}}}{f \sqrt{f} r_{\mathrm{p}}^{2}}$

In Fig. 11, the numerical results are shown. Line 1 in this diagram reflects Eq. (36); the criterion for particle deformation in the absence of Van der Waals forces. From this figure, it is clear that an increase in the interfacial energy results in a considerable increase in the maximal admissible shear modulus. Incorporation of the surface energy contribution is therefore essential when modelling particle deformation. The same calculations can be done for the case of capillary forces due to the presence of liquid bridges. The results of these calculations are not shown here, but reveal the same trend.

Note that like the Hertz theory, the JKR-theory predicts a linear relation for the elastic modulus and the reciprocal particle radius.

\subsection{Theoretical descriptions of the particle deformation based on the Yang equation}

A strong objection to the use of either the Hertz or the JKR equations is that both assume the polymer particles to be purely elastic, when in fact they are visco-elastic. However, a visco-elastic approach to film formation is much more complex due to both the time dependent mechanical properties and variations in force during particle deformation. Note that the extent of deformation is of such magnitude that a regular, linear visco-elastic approach no longer suffices and a more complex non-linear visco-elastic approach should be followed. However, such non-linear visco-elastic theory is not as yet available. In order to obtain a correct linear visco-elastic description of the particle deformation, the following integral equation should be solved [30]: $a^{3}(t)=\frac{3 r_{\mathrm{p}}}{8} \int_{0}^{t} 2 k(t-\tau) \frac{\partial F(\tau)}{\partial f} \frac{\partial f}{\partial f} \mathrm{~d} \tau$

The major problem when one attempts to solve this equation, is the fact that in general one does not know the extent of deformation as function of time. However, we have seen that in the case of deformation due to liquid bridges the magnitude of the force is nearly constant, i.e.:

$F(t)=6.2 \gamma_{\mathrm{w} / \mathrm{a}} r_{\mathrm{p}} H(t)$

where $H(t)$ is the so-called Heaviside function. Consequently, Eq. (40) can be simplified into

$a^{3}(t)=\frac{6 r_{\mathrm{p}}}{8} k(t)$

Since we have derived an expression for the contact radius, a criterion for particle deformation may be obtained; e.g. successful deformation is achieved when the radius calculated in accordance with Eq. (40) is, at least, equal to or larger than a certain minimum contact radius. Subsequently, it is merely a problem of finding an expression for the minimal contact radius. To illustrate the core of this method, we will finish by examining the following example.

\subsubsection{Example}

Two incompressible polymer spheres $(K=\infty)$ with the mechanical behaviour described by:

$G(t)=G_{0} \exp \left(-\frac{t}{\tau_{2}}\right)+G_{\infty}\left(1+\exp \left(-\frac{t}{\tau_{2}}\right)\right)$

are pressed together under constant force. Here $G_{0}$ is the instantaneous shear modulus, $G_{\infty}$ is the asymptotic modulus and $\tau_{2}$ is a characteristic relaxation time. In order to obtain an expression for the function $k(t)$, the integral Eq. (33) must be solved using Laplace transformation:

$k(t)=\frac{1}{4}\left(\frac{1}{G_{0}} \exp \left(-\frac{t}{\tau_{2}^{*}}\right)+\frac{1}{G_{\infty}}\left(1-\exp \left(-\frac{t}{\tau_{2}^{*}}\right)\right)\right) H(t)$

where $\tau_{2}{ }^{*}=\tau_{2} \mathrm{G}_{0} / \mathrm{G}_{\infty}$. Inserting Eq. (44) in Eq. (42) results in an expression for the contact radius as function of time:

$[a(t)]^{3}=\frac{3 r_{\mathrm{p}} F}{16}\left(\frac{1}{G_{0}} \exp \left(-\frac{t}{\tau_{2}^{*}}\right)+\frac{1}{G_{\infty}}\left(1-\exp \left(-\frac{t}{\tau_{2}^{*}}\right)\right)\right)$

In order to have successful deformation after $t^{*}$, the contact radius must exceed a certain minimal value:

$\left[a\left(t^{*}\right)\right]^{3} \geq a_{\min }^{3}$

In the limit of very long times, corresponding to liquid bridges, since there is always some residual water left between wetting particle, the ultimate criterion for successful particle deformation becomes: 
$\frac{3 r_{\mathrm{p}} F}{16 G_{\infty}} \geq a_{\min }^{3}$

Note that the visco-elastic problem is now simplified to an quasi-elastic problem in which the elastic modulus is replaced by the asymptotic value of the shear modulus. Furthermore, again a linear relation between elastic modulus and particle radius is predicted.

\section{Conclusions}

The different models of particle deformation presented describe a reversed proportionality between the maximal admissible shear modulus and the particle radius. However, the best experimentally obtained data [40] show no sign of this proportionality. Another important point is that no single model can explain the existence of both a 'wet' and a 'dry' MFFT. By comparing the magnitude of the different forces operative during film formation, we have shown that if one strives towards a theoretical description of film formation, one needs to take into account both the capillary force due to a receding water/air interface and that due to the presence of liquid bridges. The Van der Waals forces may give a considerable contribution at close contact. Therefore, it is recommended to use the JKR equations in order to model the particle's response to deformation, since these equations automatically incorporate any attraction between the spheres.

The existence of a 'wet' and a 'dry' MFFT points to the existence of different routes along which particle deformation may occur, as noted by Keddie et al. [37].

The 'hard' route of the Keddie model might be portrayed as film formation whereby the particles are not able to deform during the first stage, i.e. the time necessary for the particles to deform is larger than the time necessary for the water to evaporate. As a consequence, the particles are not or only partially deformed. Total deformation is, subsequently, brought on by the liquid bridges between the particles. Note that this explanation of the 'hard' route is only possible if the particles are visco-elastic. If the particles were purely elastic, the deformation would be instantaneous. As already mentioned, the mechanism of particle deformation also explains the existence of both the 'wet' and the 'dry' MFFT.

For a theoretically sound description of the particle deformation, the contact forces due to the water/air surface tension should be incorporated. In the case of purely elastic spheres, the contact force will not contribute to the force promoting deformation since, in that case, only the magnitude of the force at complete deformation - i.e. $f=0.095$ - is of importance; the particles deform instantaneously. However, in the case of visco-elastic spheres the description of the deforming process is important. Such a description requires the magnitude of the contact forces and a correct expression for the driving force as a function of the extent of deformation $f$.

The problem of the reversed proportionality, however, is not as easy to solve. Both the incorporation of liquid bridges, the inclusion of Van der Waals forces and the introduction of visco-elasticity result in the mentioned reversed proportionality. However, there is too little experimental data available at this moment to make a positive or negative judgement on the current models.

\section{References}

[1] S.G. Croll, J. Coat. Technol., 58 (1986) 41.

[2] S.G. Croll, J. Coat. Technol., 59 (1987) 81.

[3] R.E. Dillon, L.A. Matheson and E.B. Bradford, J. Colloid Sci., 8 (1951) 108 .

[4] G.L. Brown, J. Polym. Sci., 22 (1956) 423.

[5] J.W. Vanderhoff, H.L. Tarkowski, M.C. Jenkins and E.B. Bradford, J. Macromol. Chem., 1 (1966) 361.

[6] G. Mason, Br. Polym. J., 5 (1973) 101.

[7] J. Lamprecht, Colloid Polym. Sci., 258 (1980) 960.

[8] K. Kendall and J.C. Padget, Int. J. Adhes. Adhes., 2 (1982) 149.

[9] S.S. Voyutskii, J. Polym. Sci., 125 (1956) 528.

[10] E.B. Bradford and J.W. Vanderhoff, J. Macromol. Chem., 1 (1966) 335.

[11] M. Visschers, J. Laven and A.L. German, Prog. Org. Coat., 30 (1997) 39.

[12] F. London, Trans. Faraday Soc., 33 (1937) 8.

[13] H.C. Hamaker, Physica, 4 (1937) 1058.

[14] L.D. Landau and E.M.Liftshitz, Electrodymanics of Continuous Media, 2nd edn., Pergamon, Oxford, 1960.

[15] J. Israelachvili, Intermolecular and Surface Forces, 2nd edn., Academic Press, London, 1994.

[16] P.C. Hiemenz, Principles of Colloid and Surface Chemistry, 2nd edn., Marcel Dekker, New York, 1986

[17] R.J. Hunter, Foundations of Colloid Science, Vol. 1, 1st edn., Oxford University Press, Oxford, 1993.

[18] W.B. Haines, J. Agric. Sci., 20 (1930) 97.

[19] F. Lin and D.J. Meier, Proc. 21st Int. Conf. Organic Coat. Sci. Technol., 297 (1995).

[20] F. Lin and D.J. Meier, Langmuir, 11 (1995) 2726.

[21] H.M. Princen, J. Colloid Interface Sci., 30 (1969) 69.

[22] H.M. Princen, J. Colloid Interface Sci., 30 (1969) 359.

[23] H.M. Princen, J. Colloid Interface Sci., 34 (1970) 171.

[24] G. Mason and N. Morrow, J. Colloid Interface Sci., 109 (1986) 46.

[25] H. Schubert, Kapillarität in porösen Feststoffsystemen, 1st edn., Springer-Verlag, Berlin, 1982.

[26] H. Hertz, J. reine und angewandte Mathematik, 92 (1982) 156.

[27] L.D. Landau and E.M. Liftshitz, Theory of Elasticity, 3rd edn., Butterworth Heinemann, Oxford, 1986.

[28] K.L. Johnson, K. Kendall and A.D. Roberts, Proc. R. Soc. Lond. A, 324 (1971) 301.

[29] K. Kendall, Contemp. Phys., 21(1980) 3

[30] Wei Hsuin Yang, J. Appl. Mech. (Transact. ASME, Ser. E) (1966) 395.

[31] J. Lyklema, Fundamentals of Interface and Colloid Science, Vol. 1: Fundamentals, 1st edn., Academic Press, London, 1991.

[32] H.B.G. Casimir and D. Polder, Phys. Rev., 73 (1948) 360.

[33] W.B. Russel, D.A. Saville and W.R. Schowalter, Colloidal Dispersions, 1st edn., Cambridge University Press, Cambridge, 1991.

[34] G.J.M. Janssen, W.J. Soppe and B.C. Bonekarnp, J. Colloid Interface Sci., 172 (1995) 161.

[35] D.W. Van Krevelen, Properties of Polymers: Their Estimation and 
Correlation with Chemical Structure, 2nd edn., Elsevier, Amsterdam, 1976.

[36] P.R. Sperry, B.S. Snyder, M.L. O’Dowd and P.M. Lesko, Langmuir, 10 (1994) 2169.

[37] J.L. Keddie, P. Meredith, R.A.L. Jones and A.M. Donald, Macromolecules, 28 (1995) 2673.

[38] B.S. Snyder, P.R. Sperry, M.L. O’Dowd, P.M. Lesko, Z. Fu, E.
Boczar, A. Kirk, B.C. Dionne and A. Koller, Polym. Preprints, 35 (1994) 299.

[39] D.M.C. Heymans and M.F. Daniel, Polym. Adv. Technol., 6 (1995) 291.

[40] S.T. Eckersley and A. Rudin, J. Coat. Technol., 62 (1990) 89.

[41] N.D. Denkov, I.V. Ivanov and P.A. Kralchevsky, J. Colloid Interface Sci., 150 (1992) 589. 